\title{
Human factors issues in basic offshore survival and emergency training for platforms in tropical water
}

\author{
Norafneeza Norazahar ${ }^{1,2, *}$, Anwar Johari ${ }^{1,2}$, and Nur Azizah Arryanie Morshidi ${ }^{2}$ \\ ${ }^{1}$ Centre of Hydrogen Energy, Institute of Future Energy, Universiti Teknologi Malaysia, 81310 Johor \\ Bahru, Johor, Malaysia. \\ ${ }^{2}$ School of Chemical and Energy Engineering, Faculty of Engineering, Universiti Teknologi \\ Malaysia, 81310 Johor Bahru, Johor, Malaysia.
}

\begin{abstract}
The presence of human factors in escape and evacuation on offshore installations has been studied by many researchers and engineers. The studies lack of analysis on human factors in the design of emergency equipment to increase chances of success during emergencies. This paper presents the survey on basic offshore safety and emergency training for individuals working on platforms in tropical water. The main objective of the research is to identify human factors issues faced by individuals performing escape and evacuation on offshore platforms in tropical water. A set of questionnaires was distributed to 16 individuals participating in the Tropical Basic Offshore Safety Induction and Emergency Training (TBOSIET) at Terengganu Safety Training Centre, Kemaman.
\end{abstract}

\section{Introduction}

Human factor is defined as a scientific study of human interaction with a machine or other elements of a system with the purpose of optimising human and system performance [1]. According to the Health and Safety Executive [2], human factor covers environmental, organisational, and job factors, as well as individual characteristics that can influence individual's behaviour at work and affect individual's safety and health.

The integration of human factors in risk assessment has been introduced to offshore platforms after a series of major accidents $[3,4,5,6]$. The accident investigation reports reveal causes such as human errors and organisational dysfunctions as the main reasons leading to accidents. The investigation report of the BP Deepwater Horizon accident indicates that many human factors issues had affected individual's decision making and performance during the unfortunate event $[7,8]$.

The activity of escape and evacuation may not operate as accurately as planned in the emergency response plan. Uncontrolled emergency scenarios introduce chains of events that can affect individuals and their performance. The presence of evolving hazards, such as intense heat and black smoke, can also influence individual's ability in making decisions and taking actions [8]. Human factors are present in the safety barriers and emerge as

*Corresponding author: norafneeza@,utm.my 
contributing factors that lead to the failure of escape and evacuation (i.e., latent and active failures).

Late activation of an emergency alarm, ineffective command and control, communication problems, inadequate refresher training, and insufficient training as a team on offshore installations are examples of actions that could lead to human errors and poor human performance $[9,10,11,12]$. The emergency escape in the BP Deepwater Horizon accident was unsuccessful due to lack of emergency drills and exercises, poor emergency escape plan, and ineffective communication during the emergency situation [13].

\section{Objectives}

The objectives of this work are:

i) To identify human factors issues and common problems faced by individuals performing escape and evacuation on offshore platforms in tropical water, and

ii) To conduct a survey on human factors issues and safety of basic offshore survival and emergency training.

\section{Methodology}

\subsection{Escape and evacuation sequences on offshore platforms}

The existing sequence of emergency responses is adapted in many offshore platforms [14]. The sequence can be divided into three elements: i) detection system, ii) operators, and iii) individuals, as shown in Figure 1. The initiating events or hazards are detected by the detection system as illustrated in steps 1 and 2 in Figure 1. Operators are responsible to notify the emergency scenarios and start the emergency procedures as required in steps 3 to 6. From steps 7 to 14 , individuals must respond to the emergency notification and act accordingly.

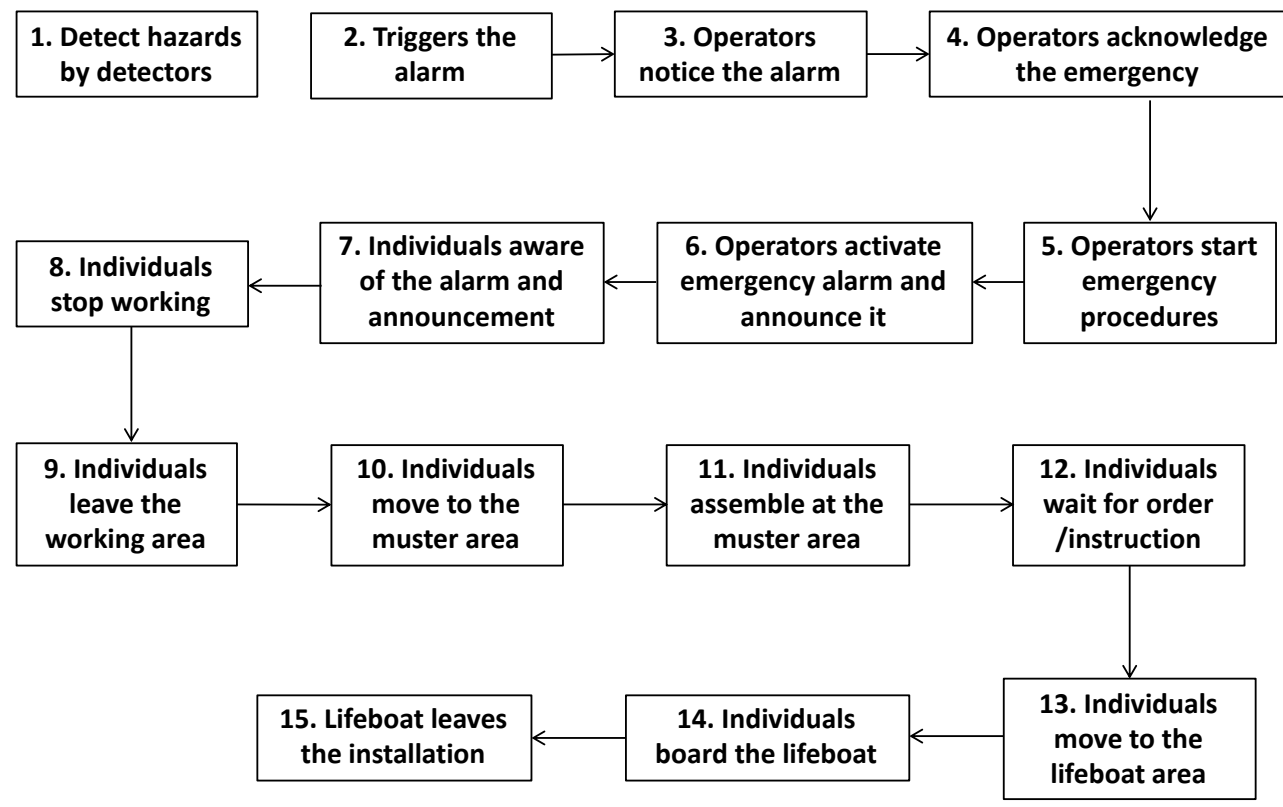

Fig. 1. The sequence of escape and evacuation on offshore platforms. 


\subsection{Collaboration with offshore safety training centre}

This study was conducted at Terengganu Safety Training Centre in Kemaman, Terengganu. The training centre provides emergency response training to individuals prior to working on offshore platforms in tropical water. The researchers discussed with the instructors of basic offshore survival training to obtain information prior to preparing the questionnaires. The information includes procedures for performing escape and evacuation, emergency equipment used in the training, the number of individuals in the training, and the number of activities to complete the emergency response training.

\subsection{Development of questionnaires}

This work used questionnaires to collect data regarding human factors issues in the escape and evacuation on offshore platforms. The questionnaires were developed based on i) information from the instructors of the training centre and ii) problems related to the emergency training, as well as the escape and evacuation operations during major offshore accidents such as that occurred during the BP Deepwater Horizon [15]. The human factors issues would include the interaction of individuals with equipment, errors made by individuals, and individuals' attitudes while performing escape and evacuation. Eight questions related to the awareness of emergency situation on offshore platforms in tropical water were prepared in this study.

The questionnaires for identifying human factors issues on basic offshore survival and emergency are as follows:

\begin{tabular}{lccccc}
\hline & $\begin{array}{c}\text { Strongly } \\
\text { Disagree }\end{array}$ & Disagree & Neither & $\begin{array}{c}\text { Agree } \\
\text { Strongly } \\
\text { Agree }\end{array}$ \\
\hline $\begin{array}{l}\text { Automatic alarm system is more reliable } \\
\text { than manual activation system. }\end{array}$ & 1 & 2 & 3 & 4 & 5 \\
$\begin{array}{l}\text { Communication between offshore } \\
\text { installations and onshore is sufficiently } \\
\text { implemented. }\end{array}$ & 1 & 2 & 3 & 4 & 5 \\
$\begin{array}{l}\text { Communication system works } \\
\text { effectively during training or drills. }\end{array}$ & 1 & 2 & 3 & 4 & 5 \\
$\begin{array}{l}\text { Backup or external communication } \\
\text { system is properly contained. }\end{array}$ & 1 & 2 & 3 & 4 & 5 \\
$\begin{array}{l}\text { Emergency alarm can be heard in the } \\
\text { cabin and/or noisy area. }\end{array}$ & 1 & 2 & 3 & 4 & 5 \\
$\begin{array}{l}\text { Announcement through public } \\
\text { announcement (PA) can be heard in the } \\
\text { cabin and/or noisy area. }\end{array}$ & 1 & 2 & 3 & 4 & 5 \\
$\begin{array}{l}\text { Installation of emergency alarm sound } \\
\text { and signal being informed to all } \\
\text { personnel on the platform. }\end{array}$ & 1 & 2 & 3 & 4 & 5 \\
$\begin{array}{l}\text { I know different types of alarm. For } \\
\text { example, emergency alarm is to notify } \\
\text { personnel to move to the muster station. }\end{array}$ & 1 & & & & 5 \\
\hline
\end{tabular}

\subsection{Training programme}

The researchers selected one classroom of training programme known as Tropical Basic Offshore Safety Induction \& Emergency Training (T-BOSIET) with Emergency Breathing System (EBS). Individuals participating in the training and survey are designated as the 
participants. The classroom consists of 16 participants. The participants must spend three days for the emergency response training. The activities of T-BOSIET are listed in Table 1. The training centre issued a license to participants who have completed all activities and passed the assessment in both classroom and practical training.

After completing the practical activities on the third day, all participants of T-BOSIET were informed regarding the research work and survey. All participants agreed to answer the questionnaires. The feedback from the survey was kept confidential. The participants could not be identified or identifiable in any report or publication.

Table 1. List of activities in the T-BOSIET group.

\begin{tabular}{|c|c|c|c|}
\hline Activities & Day 1 & Day 2 & Day 3 \\
\hline Theory & $\begin{array}{ll}\text { i. } & \text { Safety induction } \\
\text { ii. } & \text { Sea survival } \\
\text { iii. } & \text { Travel safely by boat } \\
\text { iv. Helicopter safety and } \\
\text { escape } \\
\text { v. Emergency breathing } \\
\text { system (EBS) } \\
\end{array}$ & (None) & $\begin{array}{ll}\text { i. } & \text { First aid } \\
\text { ii. } & \text { Offshore fire- } \\
\text { fighting } \\
\text { iii. Self-rescue during } \\
\text { fire }\end{array}$ \\
\hline Practical & (None) & $\begin{array}{l}\text { i. Travel safely by boat } \\
\text { ii. Helicopter safety and } \\
\text { escape } \\
\text { iii. Sea survival } \\
\text { iv. Totally enclosed motor } \\
\text { propelled survival craft } \\
\text { (TEMPSC) boarding }\end{array}$ & $\begin{aligned} \text { i. } & \text { First aid } \\
\text { ii. } & \text { Offshore fire- } \\
& \text { fighting } \\
\text { iii. } & \text { Self-rescue during } \\
& \text { fire }\end{aligned}$ \\
\hline
\end{tabular}

\section{Survey for identifying human factors issues}

The size of classroom must follow the guidelines and standards provided by OPITO [16]. The maximum number of participants allowed to attend the training in one class is 16 . The ratio of an instructor to participants is 1:16 in the theoretical part and 1:4 in the practical part. The number of participants in the class affects the sample size of the study.

Figures 2 to 9 present the results of the survey conducted on 16 participants that underwent the basic offshore survival and emergency training at Terengganu Safety Training Centre. By referring to Figure 1, step 7 shows that the participants are aware of emergency situations on platforms. Participants should be notified regarding emergency situations using emergency alarms and the public announcement system. The researchers designed a set of questionnaires focusing on the communication of emergency situations to participants.

For Question 1, 12.5\% of 16 participants disagreed that the automated emergency alarm is more reliable than the manually activated alarm. $19 \%$ of the participants are neither disagree nor agree on the reliability of the automated emergency alarm. From the survey, participants working as operators chose 'Neither' in answering the question related to the reliability of the automated emergency alarm.

In case of emergency, communication is a top priority [17]. The operators of an offshore installation must establish communication between onshore and offshore, provide effective instruction to workers, and equip installations with a backup communication. Figures 3, 4, and 5 show that all participants are either agree or strongly agree on adequate communication between onshore and offshore, effective communication implemented on platforms, and the availability of backup communication for emergency, respectively.

Questions 5 and 6 evaluated the effectiveness of audible alarms and the announcement used during emergency training or drills on offshore platforms. Majority of the participants 
stated that they could hear the emergency alarm in the cabin and/or noisy area as illustrated in Figure 6. However, one participant stated that he/she could not hear the emergency alarm. Two participants answered neither agree nor disagree, which is represented by $12.5 \%$ in Figure 7, for hearing the emergency announcement in the cabin and/or noisy area using the PA system.

$62.5 \%$ of the participants strongly agreed that they are informed on the installation of the emergency alarm as shown in Figure 8. By referring to Figure 9, the participants agreed and strongly agreed that they know different types of alarms to distinguish activities of escape and evacuation, which are represented by $68.8 \%$ and $25.0 \%$, respectively. One participant chose 'Neither' for knowing different types of alarms.

From the results of the survey, emergency alarms and public announcement are immediately used to inform participants regarding emergency situations. However, one participant reported that the use of communication is ineffective in the cabin or noisy area. The problem of not receiving information has the potential to delay participant's responses to emergency situations.

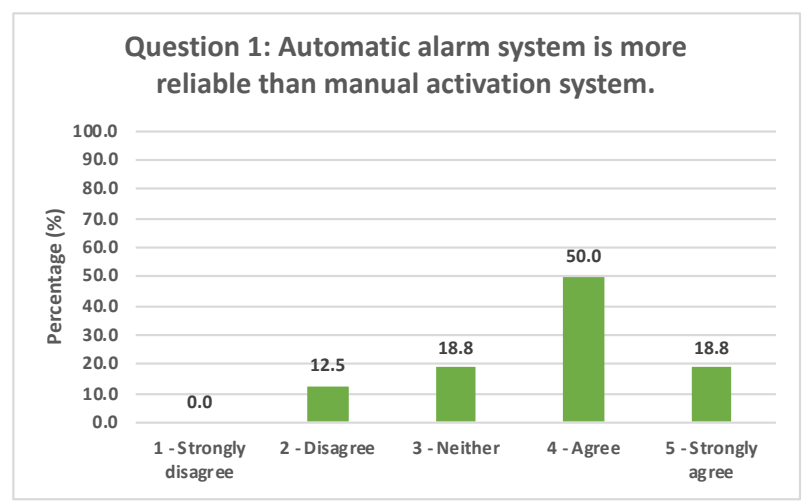

Fig. 2. Percentages for perspective on reliability of alarms.

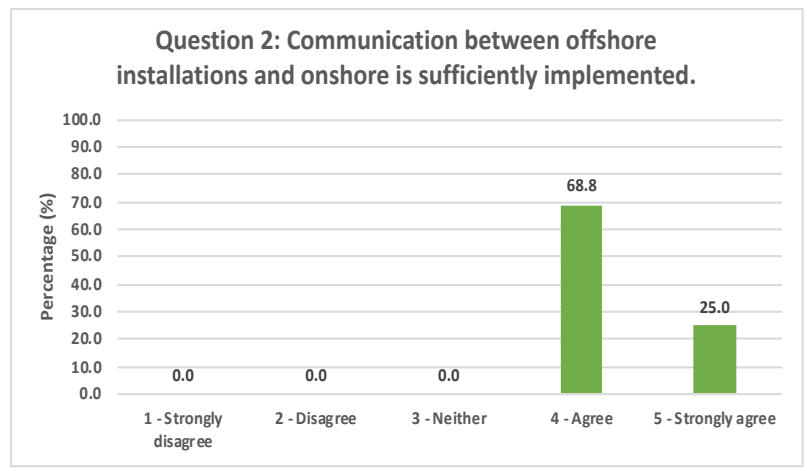

Fig. 3. Percentages for perspective on onshore and offshore communication. 


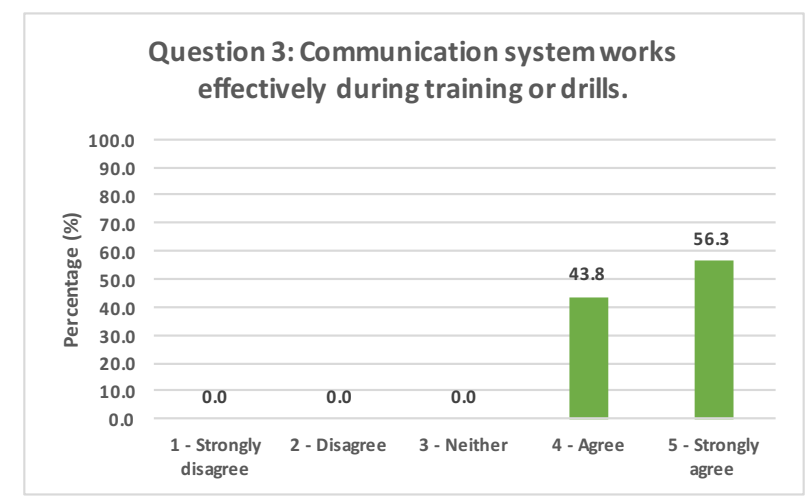

Fig. 4. Percentages for perspective on effective communication.

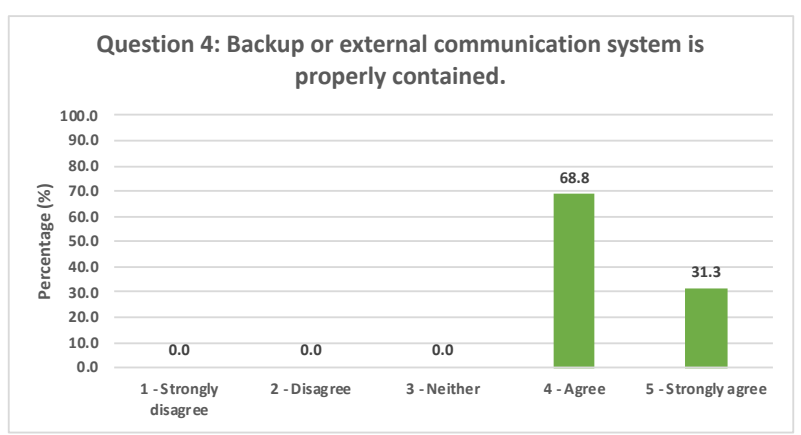

Fig. 5. Percentages for perspective on backup communication on platforms.

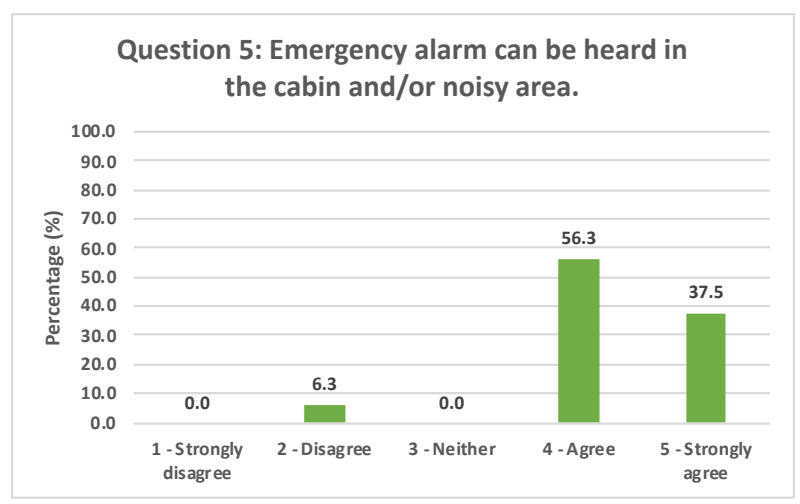

Fig. 6. Percentages for perspective on hearing alarm in the cabin and/or noisy area. 


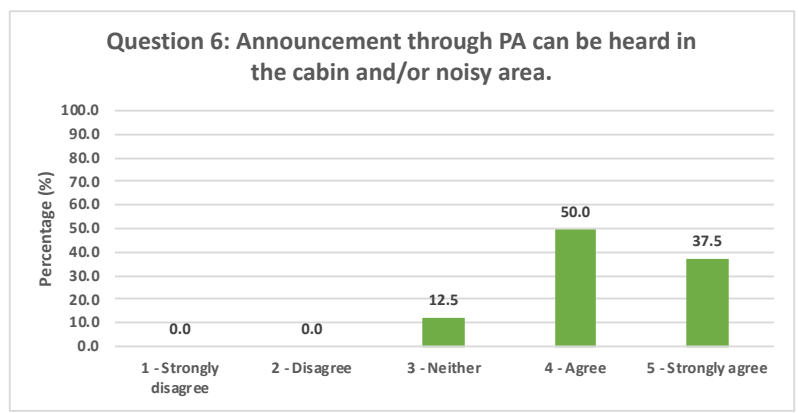

Fig. 7. Percentages for perspective on announcement through PA system.

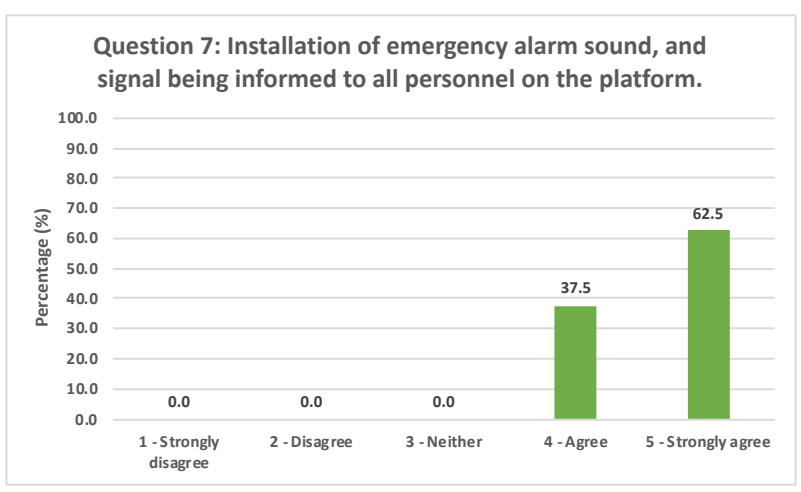

Fig. 8. Percentages for perspective on installation of emergency alarm.

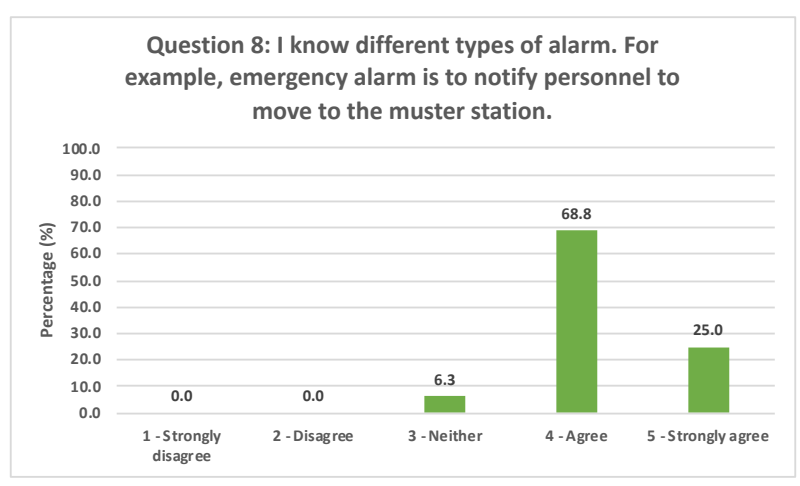

Fig. 9. Percentages for perspective on different types of alarms on platforms.

\section{Conclusion}

A survey on the awareness of emergency situations and drills on offshore platforms was conducted at Terengganu Safety Training Centre in Kemaman, Terengganu. 16 participants answered eight questions related to the use of communication for notifying emergency situations on offshore platforms. Many participants either agreed or strongly agreed with the use of communication during emergency. Participants reported that the automated emergency alarm is less reliable than the manually activated alarm. Emergency alarms and/or public announcement could not be heard in the cabin or noisy area as reported by one participant in the survey. This issue can be further studied using a bigger sample size and investigating the location of emergency alarm and public announcement on offshore platforms. 
The authors would like to acknowledge Ministry of Higher Education (MOHE) and Universiti Teknologi Malaysia (UTM) for the financial support. The cost centre number of the research funding is Q.J130000.2646.15J46 (Ref. No: PY/2017/02030). The authors would also like to thank to Terengganu Safety Training Centre for allowing the survey to be conducted.

\section{References}

1. International Ergonomics Association. Definition and Domains of Ergonomics. Retrieved from https://www.iea.cc/whats/index.html. Retrieved date: December 22, 2018.

2. Health and Safety Executive. Reducing error and influencing behaviour. Health and Safety Executive Books (2009).

3. D.G. DiMattia, F.I. Khan, P.R. Amyotte. Determination of human error probabilities for offshore platform musters. J. Loss Prev. Process Ind., 18 (2005), pp. 488-501.

4. F. I. Khan, P.R. Amyotte, D.G. DiMattia. HEPI: A new tool for human error probability calculation for offshore operation. Saf. Sci., 44 (2006), pp. 313 - 334.

5. T. Deacon, P.R. Amyotte, F.I. Khan. Human error risk analysis in offshore emergencies. Saf. Sci., 48 (2010), 803-818.

6. T. Deacon, P.R. Amyotte, F.I. Khan, S. MacKinnon. A framework for human error analysis of offshore evacuations. Saf. Sci., 51 (2013), 319 - 327.

7. Deepwater Horizon Study Group (DHSG). Final report on the investigation of the Macondo well blowout. (Center for Catastrophic Risk Management, 2011).

8. United States Coast Guard (USCG). Report of Investigation into the Circumstances Surrounding the Explosion, Fire, Sinking and Loss of Eleven Crew Members Aboard the Mobile Offshore Drilling Unit Deepwater Horizon, vol. 1. (2011).

9. B. Kennedy. A human factors analysis of evacuation, escape and rescue from offshore installations. (Health and Safety Executive Books, 1993).

10. G.W. Gould, S.Y.Z. Au. A methodology for hazard identification on EER assessments. (Health and Safety Executives, Offshore Technology Report: 466, 1995).

11. P. Boyle, E.J. Smith. Emergency planning using the HSE's evacuation, escape and rescue (EER) HAZOP technique. (Institution of Chemical Engineers, Symposium Series: Number 147, 2000).

12. B. Woodcock, Z. Au. Human factors issues in the management of emergency response at high hazard installations. J. Loss Prev. Process Ind., 26(3) (2013), pp. 547-557.

13. J.E. Skogdalen, J. Khorsandi, J.E. Vinnem. Evacuation, escape, and rescue experiences from offshore accidents including the Deepwater Horizon. J. Loss Prev. Process Ind., 25 (2012), pp. 148-158.

14. OGP. Risk Assessment Data Directory - Evacuation, Escape \& Rescue (Report No. 434 - 19). (International Association of Oil and Gas Producers, 2010).

15. N. Norazahar, F. Khan, B. Veitch, S. MacKinnon. Human and organizational factors assessment of the evacuation operation of BP Deepwater Horizon accident. Saf. Sci., 70 (2014), pp. 41-49.

16. OPITO. Tropical Basic Offshore Safety Induction \& Emergency Training T-BOSIET. 2018.

17. Health and Safety Executive. Prevention of Fire and Explosion, and Emergency Response on Offshore Installations. Health and Safety Executive Books (1997). 